\author{
Dawid Kansy \\ Wroclaw University of Economics and Business \\ e-mail: dawid.kansy@ue.wroc.pl \\ ORCID: 0000-0003-2923-9472
}

\title{
PICK UP PLAN IN THE CASE OF A SHUTTLE RACKS WAREHOUSE - AN OPTIMIZATION APPROACH
}

\section{PLAN POBRAŃ \\ W PRZYPADKU MAGAZYNU TYPU SHUTTLE - PODEJŚCIE OPTYMALIZACYJNE}

DOI: $10.15611 /$ ie.2020.1.03

JEL Classification: C60, C61

(a) 2020 Dawid Kansy

This work is licensed under the Creative Commons Attribution-ShareAlike 4.0 International License. To view a copy of this license, visit http://creativecommons.org/licenses/by-sa/4.0/

Quote as: Kansy, D. (2020). Pick up plan in the case of a shuttle racks warehouse - an optimization approach. Informatyka Ekonomiczna. Business Informatics, (1).

\begin{abstract}
The shuttle racks system is dedicated to storing fast-moving goods on homogeneous pallets, while ensuring high efficiency in the use of storage space. The radioshuttle system consist of shuttle channels and a remote controlled transfer trolley. The research problem considered scientifically is to develop the tools to plan collecting products from the location of shuttle racks that guarantee a minimum number of blockages. The linear programming model ensures that the goods are picked up from the shuttle location which minimizes the number of blockages or completely eliminates them. The main aim is to present a method and an algorithm of the shuttle racks system that will plan storage location before storing goods on the racks based on backorders. As a result, goods are located lengthwise in the shuttle tunnel according to the order in linear, discrete programming models. The work presents the model and verifies the basic characteristics of the problems analysed and the solution obtained.
\end{abstract}

Keywords: mixed-integer linear programming, optimization modeling, logistics, warehouse, shuttle racks.

Streszczenie: System regałów przepływowych typu shuttle dedykowany jest do składowania szybko rotujących towarów na jednorodnych paletach, przy jednoczesnym zapewnieniu wysokiej efektywności wykorzystania przestrzeni magazynowej. System radioshuttle składa się z kanałów shuttle i zdalnie sterowanego wózka transportowego. Rozpatrywanym naukowo problemem badawczym jest opracowanie narzędzi, których rezultatem będzie plan odbioru produktów z lokalizacji regałów przepływowych typu shuttle, gwarantujących minimal- 
ną liczbę blokad towaru. Model programowania liniowego zapewnia pobieranie towarów z miejsc składowania minimalizujących liczbę blokad lub całkowicie je eliminujących. Głównym celem artykułu jest przedstawienie metody i algorytmu systemu regałów przepływowych typu shuttle, który pozwoli zaplanować lokalizację przed składowaniem towarów w regałach, bazując na zamówieniach. W pracy przedstawiono model i zweryfikowano podstawową charakterystykę analizowanych problemów oraz otrzymane rozwiązanie.

Słowa kluczowe: programowanie liniowe, modeloweanie optymalizacyjne, logistyka, magazyn, regały przepływowe.

\section{Introduction}

Constant technological developments in warehouses have changed the main processes of storage operations, reflected in short response times of the storage and retrieval of goods, the reduction of capacity, stock and the volume of storage work as well as the automation of the entire warehouse management. Numerous companies have decided to implement automated infrastructure solutions which improve the efficiency of theirgeneral operations. An important element of automated warehouses is presented by relatively a new solution called shuttle-based storage and retrieval systems (SBS/RS).

Shuttle-based storage and retrieval systems (SBS/RS) are now widely used in modern warehouses. This is composed of multiple parallel aisles of storage racks. Theadioshuttle platform is a relatively new technology for automated unit-load, storage and reorganization. Shuttle warehouse racks have a fixed number of levels depending only on the width and height of the warehouse. The shuttle system provides storage for many pallets in relatively small area - thereby saving on the floor space and the workforce, increasing reliability and lowering error rates at the same time.

The radioshuttle platform has a significant potential advantage in the adaptability of system throughput capacity to different series of production. Market mechanisms have recently totally changed and there is now a tendency towards customization in terms of orders and production batches. Adaptation to the market requires finding solutions to the main problems. The radioshuttle platform is capable of simultaneous horizontal movements. The main impact on the efficiency of the shuttle system comes from a location allocation algorithm based on a mixed-integer decision model. The point of view must change taking into account efficiency aspects. In the traditional approach, efficiency is conditioned by the quantity of radioshuttle platforms. In the modern approach, efficiency is conditioned by many factors affecting the real course of the process. It is crucial to design a model which will take into account decision variables. It is necessary to simulate and evaluate large numbers of alternatives if the model is to run properly.

In order to simplify the performance evaluation and to facilitate decision model design, it is required to apply an efficient simulation model based on real data which can be used in the early algorithm selection or in the conceptualization phase on 
the model development. The main aim of the model is its implementation into the process area in order to generate actual benefits in the area of efficiency and quality.

The model discussed in the article is used to minimize the number of blockages in the shuttle warehouse assuming a constant order sequence. The effectiveness of the model was analysed taking into account both simple and most complicated cases. The set of tasks and test instances were defined based on real cases.

\section{General assumptions of shuttle racks}

Shuttle-based storage and retrieval system [SBS/RS] constitute a highly dynamic system with many periphrastic relationships between the decision made and their underlying components and variables. Many companies decided to install a Pallet Shuttle storage system in order to increase the available space, making full use of that space, and offers high capacity storage on a specific quantity of rack levels. The pallets are introduced into the production side (inbound process), while dispatches take place on the opposite side (outbound process), which coincides with the area allocated to the loading docks. Therefore, the channels operate using the FIFO (first in, first out) methodology, enabling a complete product turnover. Figure 1 presents the principle of operating FIFO methodology.

\begin{tabular}{|l|l|c|}
\hline OUT & $\longleftarrow$ Pallets & IN \\
\hline OUT & $\longleftarrow$ Pallets & IN \\
\hline OUT & $\longleftarrow$ Pallets & IN \\
\hline OUT & $\longleftarrow$ Pallets & IN \\
\hline OUT & $\longleftarrow$ Pallets & IN \\
\hline OUT & $\longleftarrow$ Pallets & IN \\
\hline OUT & $\longleftarrow$ Pallets & IN \\
\hline OUT & $\longleftarrow$ Pallets & IN \\
\hline
\end{tabular}

Fig. 1. FIFO flow of pallets

Source: own elaboration.

Another method is LIFO (last in, first out). In LIFO, the pallets are put into the racks on the front side of the shuttle racks and picked up on the same side of the shuttle racks. The flow is presented in Figure 2.

The main difference between the storage of pallets using normal high storage racks and using the shuttle is related to the number of pallets which can be stored in a 1500 square-meter area. Based on the author's experience, it is estimated that the shuttle racks construction allowed to store 6480 pallets in 1500 square meters, compared to normal high storage racks which only allowed to store 2200 pallets in the same space, thus relatively less than shuttle racks ( $66 \%$ less). 


\begin{tabular}{|c|c|c|c|}
\hline IN / OUT & $\stackrel{\longleftarrow}{\longleftarrow}$ Pallets & Pallets $\longleftrightarrow$ & IN / OUT \\
\hline IN / OUT & $\longrightarrow$ Pallets & Pallets & IN / OUT \\
\hline IN / OUT & $\Rightarrow$ Pallets & Pallets & IN / OUT \\
\hline IN / OUT & $\longrightarrow$ Pallets & Pallets & IN / OUT \\
\hline IN / OUT & $\longrightarrow$ Pallets & Pallets & IN / OUT \\
\hline IN / OUT & $\longrightarrow$ Pallets & Pallets & IN / OUT \\
\hline IN / OUT & $\longrightarrow$ Pallets & Pallets & IN / OUT \\
\hline IN / OUT & 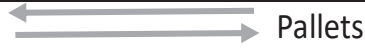 & Pallets & IN / OUT \\
\hline
\end{tabular}

Fig. 2. LIFO flow of pallets

Source: own elaboration.

The issue of effective use is currently the most crucial one, but companies actually do not have adequate facilities to manage it. In many cases, companies which offer a storage racks system do not take into account the limitations resulting from the specific aspects of the company's operations, hence the real parameters of the storage system do not match the parameters declared by the manufacturer. This always entails a series of events which have an influence on operational processes. Every logistics project is based on certain assumptions. Preliminary estimates assume the parameters given by the manufacturers, but the actual functioning of the process is quite different in many cases when compared to the initial assumptions. This causes the underestimation of the real storage capacity, the volume of the pallet flow and the pallet rotation time. These factors have a direct impact on process delays. The constraints that can be distinguished are based on the above issues:

1) warehouse layout - warehouse designed only for long production series, which causes inefficient warehouse space;

2) constraints of planning goods collection - the goods are blocked for pickup by other goods (this is the case when using the shuttle channel maximally and two or more type of goods have been placed in the same location);

3) lack of information about production plan - goods are placed at random locations without consolidation and rotation criterion;

4) unavailability of information about schedule of customer orders - to prepare goods earlier and adapt the warehouse to subsequent operations;

The paper is organized as follows: Section 1 presents the introduction. Section 2 describes the contribution of the shuttle racks warehouse. Section 3 discusses the general assumptions of shuttle racks found in the literature concerning warehouse systems. Section 4 shows the shuttle racks design and shuttle racks operations along with the assumptions of the decision model. Section 5 consists in the simulations of the model containing real data and typical decision problems during the main processes - namely the process of receiving goods and the delivery of goods. Finally, the author presents the conclusions and recommendation of further research. 


\section{Review of literature on automated storage and decision planning models for automated storage}

\subsection{Classification of automated storage and decision planning models}

Automated storage and retrieval have been extensively used in distribution and production processes since their introduction in the 1950s. Automated storage usually consists of racks served by cranes running through aisles between the racks.

Automated racks technology is capable of handling pallets without the participation of an operator, thus the system is fully automated and every movement is controlled by system which minimalizes any errors. Both in production and distribution environments automated, storage systems are used for putting products in storage and retrieving products from storage to fulfill an order. Between 1994 and 2004 , there was a significant increase in the number of different types of automated storage systems used in distribution environments.

In order to clarify the terminology of automated systems, below are listed the main types of automated systems:

1. AS/RS - Autonomous Storage and Retrieval System.

2. SBS/RS - Shuttle-based and Retrieval System.

3. AVS/RS - Autonomous Vehicle Storage and Retrieval System.

4. SP-AS/RS - Split-Automated Storage and Retrieval System.

5. CBAS/RS - Crane-based Automated Storage and Retrieval System.

An Automated Storage and Retrieval System is defined as a storage system that uses fixed-path storage and retrieval machines running on one or more rails between fixed arrays of storage racks. AS/RS are typically used to store and retrieve loads in many various options. A typical AS/RS system consists of racks, cranes, aisles, input/output points and pick positions. Racks are metal structures in the locations that can accommodate loads that need to be stored. Cranes are the fully automated storage and retrieval machines that can autonomously move, pick up and drop off loads. Aisles are regularly formed by the empty spaces between the racks, where the cranes can move. An input/output point is a location where retrieved loads are dropped off, and where incoming loads are picked up for storage. Pick positions are places where people are working to remove individual items from a retrieved load before the load is sent back into the system.

A Shuttle-Based Storage and Retrieval System is a relatively new autonomous technology, but no research has been completed on their operations. Many studies focused on AS/RS, which are configured similarly to SBS/RS. AVS/RS and SP$\mathrm{AS} / \mathrm{RS}$ which have been developed as a substitute/replacement to the CBAS/RS to relocate heavy loads. In contrast to the CBAS/RS system, the SP-AS/RS system has one vertical platform and a specific number of horizontal platforms. Therefore SP$\mathrm{AS} / \mathrm{RS}$ and SBS/RS are different in terms of cargo types. The infrastructure designs of SP-AS/RS and SBS/RS are similar. 


\subsection{Classic approach to automated storage}

Automated systems has been discussed by numerous researchers. Warehouses in the supply chain have moved beyond manual movements using people, towards AVS/ RS offering additional flexibility and improved efficiency in warehouse operations. The throughput capacity of autonomous technology can be varied by changing the number of autonomous vehicles in the warehouse infrastructure. The main components included in the AVS/RS system are lifts and automated vehicles in the racks area. Lifts are dedicated to vertical movements, while autonomous vehicles provide horizontal movements. It has to be emphasized that an autonomous vehicle storage system is implemented by companies for heavy unit-load transactions (Malmborg, 2002, pp. 1807-1822). Roodbergen and Vis (2009) provided a detailed review of AVS/RS. They established categories of design decisions - physical design and control policies. Physical design is linked to physical configurations including construction factors. The completely different role is played by control policies to determine the actions conducted by the system e.g. the WMS system. The control policy is composed of storage assignments, batching, sequencing and dwell points (Roodbergen and Vis, 2009). Other researchers include additional factors concerning the autonomous vehicle and retrieval system.

Ya-Hong et al. (2005, pp. 1515-1544), Vasili, Tang, Homayouni, and Ismail (2008, pp. 824-840), and Liu, Xu, Qin, and Lim (2015, pp. 442-460) focus on the Split-Automated Storage and Retrieval System. The AVS/RS system was developed in order to increase system flexibility compared to the CBAS/RS system. Vehicles moving controlled unit loads horizontally along shuttle channel (otherwise called "guide rails") within storage racks included vertical movement using lifts equipped along the racks infrastructure (Zizzi, 2000). Therefore the Automated Storage and Retrieval System is more effective and productive within channels, and AVS/RS is definitely flexible in the throughput capacity for the transactions. The Autonomous Vehicle Storage and Retrieval Systems ensure the effective functioning of the shuttle system and even transaction demands, because the designers can modify the number of shuttle racks devices depending on the transaction volume in the system. Most of the articles were written about AVS/RS (Malmborg, 2002, pp. 1807-1822; Fukunari and Malmborg, 2008, pp. 3167-3184).

Krishnamurthy, Roy, Heragu, and Charles (2010) focused on the research on the blocking effect on vehicles in AVS/RS and concentrated on protocols to address the blocking of a vehicle's way and suggested a simulation model in order to assess the effects of blocking. The study established analytical models (Malmborg, 2003, pp. 1057-1069) and a simulation model (Ekren, Heragu, Krishnamurthy, Malmborg, and Charles, 2010). The above described models did not reflect real blocking or the interference of vehicles during transactions.

Other authors, e.g. Lienert, Fotter, He and Luo, examined deadlock control in the Autonomous Vehicle and Retrieval System. They achieved the avoidance of 
deadlock based on CTPN [Colored Timed Petri Net model] and the time window routing method. Current methods of deadlock avoidance are not appropriate for the Shuttle-Based Storage and Retrieval System. The research concerned deadlock avoidance within one shuttle level rather than on system performance. Additionally, the studies did not address the possibility of moving vehicles from one shuttle level to another. Therefore, Lienert, Fotter, He and Luo did not analyse the inefficiencies resulting from the disparities in the number of autonomous vehicles between shuttle levels (Lienert and Fottner, 2017; He and Luo, 2009, pp. 3253-3263).

\subsection{The modern approach to automated storage - decision planning models for automated storage}

The first study on SBS/RS is completed by Carlo and Vis, and examined the ShuttleBased Storage and Retrieval System developed by Vanderlande Industries where non-passing lifting systems are mounted along the rack. In that paper, they focused on the scheduling problem of lifts where two (piecewise linear) functions are introduced to evaluate candidate solutions. They developed an integrated look-ahead heuristic for the solution procedure to improve the total handling time (in terms of throughput) (Carlo and Vis, 2012, pp. 844-853). Marchet modelled an SBS/RS via the open queuing network to estimate the real performance of the system in terms of utilization of efficiency of lifts and shuttles as well as waiting times for lifts and queues. To validate in detail the analytical models, they used simulation modelling. The developed analytical models exhibited good estimates for the performance measures (Marchet, Melacini, Perotti, and Tappia, 2012, pp. 7134-7148). Moreover, in the later period Marchet presented the main design trade-offs for the Shuttle-Based Storage and Retrieval System using a special simulation. In order to complete the study, design scenarios for tier captive shuttle vehicles were implemented for several warehouses. It presented performance measures from the system, i.e. indicators concerning utilizing lifts and shuttles, average flow time, waiting time as well as cost dedicated to the pre-defined rack design (Marchet, Melacini, Perotti, and Tappia, 2013, pp. 4365-4387).

Further research was carried out by Lerher who studied SBS/RS by considering the energy efficiency concept in the system design. Lerher developed a simulationbased performance evaluation of the SBS/RS in order to defined system bottlenecks (Lerher, Ekren, Banu, and Sari, 2015, pp. 48-59). The author defined an analytical travel time model to calculate in detail the SBS/RS travel time. Another element is the travel time model divided into one model for the future horizontal direction and another for the vertical direction. The travel time model was examined to compare it to the simulation model (Lerher, Ekren, Dukic, and Rosi, 2015, pp. 1705-1725).

The proposed models provide several warehouse designs and their performances (Lerher, Edl, and Rosi, 2014, pp. 97-115). The models were considered in terms of velocity profiles of lift, and additionally take into account shuttle carriers, while their 
performances were considered in respect of amount of energy consumption, amount of CO2 oscillation and efficiency (Lerher, 2013, pp. 51-86).

Another approach was presented by Smew, who developed a simulation study to achieve a trade-off between the conflicting objectives of improving the customer service level and minimizing Work-In-Process (Smew, Young, and Geraghty, 2013, pp. 178-189).

However, Bekker suggested a computational approach to optimize and improve efficiency rate and a completely allocated buffer space, which are two conflicting objectives of the buffer space allocation problem (Bekker, 2013, pp. 50-61).

Another conclusion was presented by Berlec et al., who studied the calculation of optimal batch quantity using the first basic model. The extended model took into account the capital tied-up in production, in addition to the costs of changing the batch and storage costs. The study was aimed to find out when either of the two models should be used (Berlec, Kusar, Zerovnik, and Starbek, 2014, pp. 35-42).

In contrast to actual studies, the approach concerning SBS/RS is closely related to the storage rack design and configuration profiles for shuttle platforms (autonomous vehicles) by using simulation modelling (Erkan and Can, 2014, pp. 87-93). The strategies concerning shuttle control are necessary to obviate conflict in tier-to-tier SBS/RS. Shuttle-based systems have only recently been developed and research has not yet been carried out on their operations. Therefore, the literature about the removal of tier-to-tier SBS/RS conflict is mostly associated with Automated Guided Vehicle Systems. Three authors, Giordano, Dotoli and Fanti, studied automated and autonomous warehouse system control and concentrated on system performance via fully integrated supervision. The authors implemented unidirectional guiderails,applying an Rail Guided Vehicle in a single line to deliver multiple SKUs, whereby RGV collisions were eliminated. This is the main difference with SBS/RS, where shuttle interference is a primary concern (Dotoli and Fanti, 2005, pp. 122-136; Giordano, Zhang, Naso, and Lewis, 2008).

Ekren (2016) concentrated on a graph-based solution used for the design of SBS/ RS systems. The graph-based presentation contains an extensive design concept which included the number of bays, aisles and tiers dedicated for rack design and arrival rate of the $\mathrm{S} / \mathrm{R}$ transaction.

Wang used a different approach, and converted a task scheduling problem into an assembly line parallel task problem and implemented a non-dominated sorting algorithm, NSGA-II, to completely solve a multi-objective job schedule model. Later studies proved that the algorithm functioned properly and effectively by using it to conduct a case study. The research concerned free balancing, avoiding collisions/ blockages in the shuttle channel, blocking delays and the occurrenece of bottlenecks. The research contributed to improving total system efficiency such as resource utilization and throughput capacity (Wang, Mou, and Wu, 2015, pp. 5884-5895).

Le-Anh and Koster described four categories associated with avoiding collision, namely balancing the system workload, forward sensing, controlling the traffic at 
intersections and zone planning. The latter was used in the research below (Le-Anh and De Koster, 2006, pp. 1-23). Zone planning strategy partitions the systems into non-overlapping places and reduces the presence of the autonomous vehicle to one per zone. The zone planning category should be classified into two subcategories. The first is static zoning, the second is dynamic zoning. The main difference between them is the flexibility concerning a specific zone. A dynamic zone can be changed according to the traffic flow in the system, while a static zone cannot change the area. Le-Anh and Koster distinguished four categories from a conceptual point of view. The first one is deadlock-ignoring, the second deadlock prevention, the third deadlock avoidance and the last is deadlock detection and recovery $(\mathrm{Li}$, NaiQi, and MengChu, 2012, pp. 437-462). One of these subcategories, deadlockignoring, cannot be used in SBS/RS because of the probability that deadlocks are not irrelevant. The second subcategory - deadlock detection and recovery - are based on the deterministic timing of autonomous vehicles and for this reason this category in not applicable to a dynamic system. However, deadlock prevention refers to static goods allocation to avoid deadlocks (Viswanadham, Narahari, and Johnson, 1990, pp. 713-723).

The principle of operations can be presented by this example: before an allocation process starts, all the important and required resources should be prepared in advance based on assumptions. Therefore, because of this, the parameters and characteristics, and the prevention of deadlocks denote poor and inefficient use of resources. Based on previous activities, deadlock-ignoring strategy, deadlock detection and recovery strategy and deadlock prevention strategy, are not suitable for free-balancing.

The second issue is strategy related to avoid using dynamic resource allocation system. The system controls the current status and decides if one shuttle channel exists. The strategy provides a limitation of deadlock occurrences in the field of automated guided vehicles or autonomous vehicle storage and the retrieval system. The optimal functioning of the shuttle system is related to infrastructure which includes autonomous, independently moving vehicles. The second case is enough operational space in order to avoid the deadlock. The implemented configuration, despite delays, simply allows deadlock control. A deadlock avoidance strategy is not suitable for shuttle-based and retrieval systems because shuttles are not possible to move independently in vertical directions. This fact significantly limits the flexibility of the system. Another case is the movement of shuttles. Shuttles use the elevator to move between levels of shuttle racks. Considering the difference between the AVS/RS and the SBS/RS system, two key factors must be taken into account. AVR/RS systems must also use the elevator for movements between levels. In the AVR/RS system, it is not necessary to avoid deadlock because it has alternatives to avoid deadlocks/blockages. Shuttles which are adapted for the SBS/RS system are required to move between shuttle racks levels in order to avoid deadlocks/blockages. The SBS/RS system shows an increased number of moves between levels, which causes the blocking of the shuttle channel and poor efficiency. As a result, there 
is not enough space in the shuttle racks to completely avoid deadlocks/blockages. The autonomous shuttle vehicle can move on guide-rail line parallel, and this has a critical impact based on system performance. Compared to the AVS/RS system, the SBS/RS system uses a single active shuttle. Other shuttle vehicles in the same shuttle channel would be prevented from moving and occupy space in the shuttle racks. In order to solve the problem and manage the shuttle racks properly it was necessary to implement a decision model, and as a result deadlock/blockages control and increased efficiency were achieved.

In Polish literature, the problem of optimization in SBS/R systems has not yet been considered. Most attention was given to the traditional picker-to-part warehouses where storage and order-picking processes strictly interact. For example, Kłodawski (2014) analysed the issue of storage location assignment using analytical models. Additionally Kłodawski, Jachimowski, Jacyna-Golda, and Izdebski (2018, pp. 431-443 ), used the simulation model to solve the congestion problem.

\section{Assumptions of the decision model}

In this part of the article a decision model of linear programming was defined. The result of the model determined the location of subsequent pickups.

The simulation model begins with the process of defined infrastructures of racks according to the prescribed shuttle storage area.

The following assumptions of the model were formulated:

\section{Indexes}

series of channels

$j \in J$ series of pallet places

$t \in T$ series of periods of time

$k \in K$ series of products

\section{Parameters}

$d_{k, t}$ demand for product $k$ in period $t$

$s_{i, j}$ product number in channel $i$ and place of pallet $j$

\section{Decision variables}

$x_{i, j}$ the period of product collection from channel $i$ and place $j$

$y_{i, j, t}$ the binary variable takes its $(=) 1$ if from channel $[i]$ and place $[j]$ in period $[t]$ the product was taken

$z_{k, t}$ the number of missing products $[k]$ in period $[t]$

objective function - minimization of blockages

$$
\sum_{k \in K, t \in T} z_{k, t} \rightarrow \min .
$$




\section{Constraints}

$$
x_{i, j} \leq x_{i, j+1} \text { for every } i \in I \text { and } j \in J \backslash|J|
$$

date of collection from the next pallet place cannot be earlier than from the nearest place

$$
d_{k, t} \leq \sum_{\left\{i, j \mid s_{i, j}=k\right\}} y_{i, j, t}+z_{k, t} \quad \text { for every } k \in K \text { and } t \in T
$$

the total demand in period $t$ cannot be higher than the number of pallets estimated to be delivered in one period for one specific product

$$
\sum_{t \in T} y_{i, j, t} \leq 1 \text { for every } i \in I \text { and } j \in J
$$

only one pallet product in one place (channel and pallet place)

$$
x_{i, j}=\sum_{t \in T} t y_{i, j, t} \text { for every } i \in I \text { and } j \in J .
$$

The relation of decision variable $\mathrm{x}$ and $\mathrm{y}$

$$
x_{i, j} \geq 0 \quad \text { for every } i \in I \text { and } j \in J \text { and } s_{i, j}>0 .
$$

The availability date must be higher than the zero period for each place where there is stock.

The assumptions above were used to create a decision model that allowed to identify deadlocks/blockages in shuttle racks. In the case of using linear discrete programming, the model can be implemented to an application which presents the simulation including all the above indexes, parameters, decision variables and constraints. Based on the established data, assumptions can be implemented to dedicate the application in order to run a simulation. If the analytical decision models are implemented in specific software, it is difficult for warehouse designers who do not have an adequate background or direct access to the analytical models, or the software to use them. However, a web interface based on a decision model should provide a user-friendly interface in order to be easily implemented in warehouse operation processes. As a rule, users do not need to know the details of the algorithm used to solve the basic problems of shuttle racks. It is necessary to design a decision model based on user preferences and warehouse infrastructure - this is the key to success.

\section{Computational results - simulation of the model containing real data analysis}

The simulation was created to analyse the effects of implementing the decision model. The simulation controls the radioshuttle vehicles' position by using transaction process logic, and storage locations by applying a plan of production and 
customer order information. The efficiency of the system can change depending on the combination of the production plan and customer order, because these factors correlate with one another. The considerations below determine the appropriate logic combinations in order to maximize each effect. This section contains an explanation of the simulation assumptions. The decision model for the SBS/RS was described in detail.

The main assumptions of the first decision model are:

- Based on real system observation, including the warehouse stock, location of products and pick up schedule (orders), the model shows in advance when the product will be blocked and what product will be unavailable from stock.

The first step was the verification of shuttle racks filling, because employees who use shuttle racks do not have a tool for the effective filling of shuttle racks. Pallets are stored randomly which causes ineffective capacity of shuttle racks. In order to implement the proper solution for the problem, data are required. Based on real data from the WMS system, it was possible to create the tool which gives information about current filling of shuttle racks.

The second step generated various test examples. The parameters included in the model were modifiable to obtain a set of test cases. The solution time and the number of blockages were analysed as test results.

The main components of the results were as follows:

1) solution time,

2) number of constraints,

3) number of variables,

4) number of iterations.

In order to properly understand the dependencies between the locations of products and the pick up schedule (orders), it is necessary to interpret the results of the simulation. For the proper interpretation of the analysis, it was required to clarify the tables below. Table 1 presents the location of products in the warehouse - the vertical axis shows the number of channels inside the shuttle racks, while the horizontal axis shows the product number on the indicated pallet place. The interpretation of the table contents is as follows:

- in the second pallet place, in the third channel, product $\mathrm{C}$ is located,

- in the third pallet place, in the first channel, product $\mathrm{H}$ is located,

- in the fourth pallet place, in the second channel, product B is located.

Table 2 presents the order quantity - the vertical axis shows the products, while the horizontal axis shows the time period (the unit of time is a day). Table 2 shows the products that are included in the order in the indicated period. Going to the next part of the analysis, it is necessary to relate the stock level of the warehouse to the orders. This relation is presented in Table 3. Based on this, it is possible to identify the available stock level, which is one of the variables used to conduct test instances. However, before one gets to the test examples, the process must be clarified. When considering the design of shuttle racks, one should take into account the constraints 
Table 1. Location of products in the warehouse

\begin{tabular}{|c|c|c|c|c|c|c|c|c|}
\hline & \multicolumn{7}{|c|}{ Location of products in the warehouse } \\
\hline & & \multicolumn{7}{|c|}{ Product number on the indicated pallet place } \\
\hline & & 1 & 2 & 3 & 4 & 5 & 6 & 7 \\
\hline \multirow{30}{*}{ 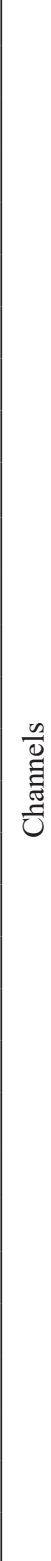 } & 1 & A & $\mathrm{H}$ & $\mathrm{H}$ & A & A & $\mathrm{D}$ & $\mathrm{F}$ \\
\hline & 2 & B & $\mathrm{B}$ & $\mathrm{B}$ & $\mathrm{B}$ & $\mathrm{B}$ & G & $\mathrm{I}$ \\
\hline & 3 & B & $\mathrm{C}$ & $\mathrm{E}$ & $\mathrm{C}$ & $\mathrm{C}$ & $\mathrm{E}$ & $\mathrm{I}$ \\
\hline & 4 & A & $\mathrm{B}$ & $\mathrm{F}$ & $\mathrm{E}$ & $\mathrm{E}$ & $\mathrm{F}$ & I \\
\hline & 5 & B & $\mathrm{B}$ & G & $\mathrm{F}$ & $\mathrm{H}$ & $\mathrm{H}$ & $\mathrm{H}$ \\
\hline & 6 & $\mathrm{~B}$ & $\mathrm{~B}$ & C & $\mathrm{G}$ & $\mathrm{G}$ & $\mathrm{F}$ & $\mathrm{G}$ \\
\hline & 7 & A & B & $\mathrm{G}$ & C & $\mathrm{C}$ & $\mathrm{C}$ & $\mathrm{F}$ \\
\hline & 8 & $\mathrm{C}$ & $\mathrm{E}$ & $\mathrm{H}$ & $\mathrm{D}$ & $\mathrm{E}$ & B & $E$ \\
\hline & 9 & $\mathrm{C}$ & $\mathrm{E}$ & $\mathrm{H}$ & $\mathrm{F}$ & $\mathrm{F}$ & $\mathrm{D}$ & A \\
\hline & 10 & $\mathrm{C}$ & $\mathrm{E}$ & $\mathrm{H}$ & $\mathrm{H}$ & $\mathrm{G}$ & $\mathrm{E}$ & A \\
\hline & 11 & $\mathrm{C}$ & $\mathrm{E}$ & $\mathrm{H}$ & $\mathrm{J}$ & $\mathrm{C}$ & $\mathrm{F}$ & A \\
\hline & 12 & $\mathrm{C}$ & $\mathrm{E}$ & $\mathrm{H}$ & $\mathrm{D}$ & $\mathrm{D}$ & $\mathrm{F}$ & D \\
\hline & 13 & A & $\mathrm{E}$ & $\mathrm{J}$ & $\mathrm{C}$ & $\mathrm{E}$ & $\mathrm{F}$ & $\mathrm{D}$ \\
\hline & 14 & $\mathrm{C}$ & $\mathrm{E}$ & $\mathrm{J}$ & B & $\mathrm{F}$ & $\mathrm{F}$ & $\mathrm{D}$ \\
\hline & 15 & $\mathrm{C}$ & $\mathrm{E}$ & $\mathrm{J}$ & $\mathrm{F}$ & $\mathrm{G}$ & $\mathrm{D}$ & $\mathrm{E}$ \\
\hline & 16 & $\mathrm{C}$ & $E$ & $\mathrm{~J}$ & $\mathrm{G}$ & B & $\mathrm{C}$ & E \\
\hline & 17 & A & $\mathrm{E}$ & $\mathrm{D}$ & B & $\mathrm{C}$ & B & $\mathrm{E}$ \\
\hline & 18 & $\mathrm{C}$ & $\mathrm{F}$ & $\mathrm{D}$ & C & $\mathrm{D}$ & B & $\mathrm{F}$ \\
\hline & 19 & $\mathrm{C}$ & $\mathrm{F}$ & $\mathrm{C}$ & $\mathrm{D}$ & $\mathrm{E}$ & B & $\mathrm{F}$ \\
\hline & 20 & A & $\mathrm{F}$ & $\mathrm{C}$ & $\mathrm{E}$ & $\mathrm{G}$ & $\mathrm{D}$ & $\mathrm{F}$ \\
\hline & 21 & $\mathrm{C}$ & $\mathrm{F}$ & $\mathrm{C}$ & $\mathrm{F}$ & $\mathrm{F}$ & $\mathrm{E}$ & $\mathrm{F}$ \\
\hline & 22 & $\mathrm{C}$ & $\mathrm{J}$ & $\mathrm{C}$ & $\mathrm{E}$ & $\mathrm{D}$ & $\mathrm{F}$ & $\mathrm{F}$ \\
\hline & 23 & $\mathrm{C}$ & $\mathrm{J}$ & B & $\mathrm{F}$ & $\mathrm{C}$ & $\mathrm{G}$ & $\mathrm{G}$ \\
\hline & 24 & $\mathrm{C}$ & $\mathrm{J}$ & B & $\mathrm{J}$ & $\mathrm{C}$ & $\mathrm{G}$ & $\mathrm{G}$ \\
\hline & 25 & $\mathrm{C}$ & $\mathrm{D}$ & B & $\mathrm{J}$ & $\mathrm{F}$ & $\mathrm{G}$ & $\mathrm{G}$ \\
\hline & 26 & $\mathrm{~A}$ & A & I & $\mathrm{H}$ & $\mathrm{E}$ & $\mathrm{E}$ & $\mathrm{G}$ \\
\hline & 27 & $\mathrm{C}$ & I & $\mathrm{J}$ & $\mathrm{G}$ & $\mathrm{D}$ & $\mathrm{D}$ & $\mathrm{H}$ \\
\hline & 28 & $\mathrm{C}$ & I & $\mathrm{E}$ & $A$ & $\mathrm{C}$ & $\mathrm{D}$ & $\mathrm{H}$ \\
\hline & 29 & $\mathrm{C}$ & $\mathrm{C}$ & $\mathrm{F}$ & A & $\mathrm{D}$ & $\mathrm{D}$ & $\mathrm{H}$ \\
\hline & 30 & A & $\mathrm{C}$ & $\mathrm{G}$ & $A$ & $\mathrm{E}$ & $\mathrm{C}$ & $\mathrm{H}$ \\
\hline
\end{tabular}

Source: own elaboration. 
Table 2. Order quantity

\begin{tabular}{|c|c|c|c|c|c|c|}
\hline & \multicolumn{5}{|c|}{ Order quantity } \\
\hline & & \multicolumn{5}{|c|}{ Time period [days] } \\
\hline & & 1 & 2 & 3 & 4 & 5 \\
\hline \multirow{10}{*}{ 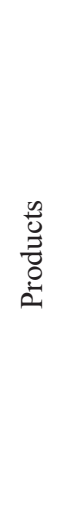 } & A & 9 & & 7 & & 1 \\
\hline & $\mathrm{B}$ & 3 & 4 & 3 & 1 & 2 \\
\hline & $\mathrm{C}$ & 2 & 2 & 5 & 4 & 1 \\
\hline & D & 9 & 4 & & 8 & \\
\hline & $\mathrm{E}$ & & 8 & 1 & 5 & 6 \\
\hline & $\mathrm{F}$ & 13 & & 12 & & \\
\hline & G & 6 & 1 & & 3 & 2 \\
\hline & $\mathrm{H}$ & 2 & 1 & & & 2 \\
\hline & $\mathrm{I}$ & & & & & \\
\hline & $\mathrm{J}$ & 8 & & & & 3 \\
\hline
\end{tabular}

Source: own elaboration.

Table 3. Stock level in relation to orders

\begin{tabular}{|c|c|c|c|c|}
\hline \multirow{12}{*}{$\begin{array}{l}\tilde{0}_{0}^{0} \\
\frac{0}{0} \\
0 \\
0\end{array}$} & \multicolumn{2}{|c|}{ Stock level } & Order quantity & $\begin{array}{l}\text { Available stock level after } \\
\text { reservation quantities } \\
\text { of products to orders }\end{array}$ \\
\hline & \multicolumn{2}{|c|}{ Unit - pallets } & Unit - pallets & Unit - pallets \\
\hline & A & 17 & 17 & 0 \\
\hline & $\mathrm{B}$ & 22 & 13 & 9 \\
\hline & $\mathrm{C}$ & 40 & 14 & 26 \\
\hline & $\mathrm{D}$ & 21 & 21 & 0 \\
\hline & $\mathrm{E}$ & 28 & 20 & 8 \\
\hline & $\mathrm{F}$ & 29 & 25 & 4 \\
\hline & G & 19 & 12 & 7 \\
\hline & $\mathrm{H}$ & 15 & 5 & 10 \\
\hline & I & 6 & 0 & 6 \\
\hline & $\mathrm{J}$ & 11 & 11 & 0 \\
\hline
\end{tabular}

Source: own elaboration.

during the storage processes. The warehouse employee prepares orders based on the dispositions from the Warehouse Managament System received on the mobile terminal. From the WMS system's point of view, only product compatibility is crucial, so when the same products appear in different shuttle channels, the system will indicate 
Table 4. Delivery date

\begin{tabular}{|c|c|c|c|c|c|c|c|c|}
\hline & \multicolumn{7}{|c|}{ Delivery date [days] } \\
\hline & & \multicolumn{7}{|c|}{ Number of pallet place inside the channel } \\
\hline & & 1 & 2 & 3 & 4 & 5 & 6 & 7 \\
\hline \multirow{30}{*}{ 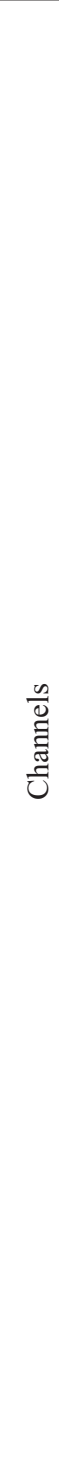 } & 1 & 1 & 1 & 1 & 1 & 1 & 2 & 3 \\
\hline & 2 & 1 & 1 & 1 & 1 & 2 & 4 & 5 \\
\hline & 3 & 2 & 2 & 2 & 3 & 4 & 4 & 5 \\
\hline & 4 & 1 & 1 & 1 & 2 & 4 & 5 & 5 \\
\hline & 5 & 1 & 2 & 4 & 5 & 5 & 5 & 5 \\
\hline & 6 & 1 & 1 & 1 & 1 & 1 & 1 & 1 \\
\hline & 7 & 1 & 1 & 1 & 1 & 1 & 1 & 1 \\
\hline & 8 & 1 & 1 & 1 & 1 & 2 & 4 & 4 \\
\hline & 9 & 1 & 1 & 1 & 1 & 1 & 1 & 3 \\
\hline & 10 & 1 & 1 & 1 & 1 & 1 & 4 & 5 \\
\hline & 11 & 1 & 1 & 1 & 1 & 1 & 3 & 3 \\
\hline & 12 & 1 & 2 & 2 & 4 & 4 & 4 & 4 \\
\hline & 13 & 1 & 1 & 1 & 2 & 2 & 3 & 4 \\
\hline & 14 & 1 & 1 & 1 & 1 & 1 & 1 & 4 \\
\hline & 15 & 1 & 1 & 1 & 1 & 2 & 2 & 5 \\
\hline & 16 & 1 & 2 & 5 & 5 & 5 & 5 & 5 \\
\hline & 17 & 1 & 1 & 1 & 1 & 3 & 3 & 5 \\
\hline & 18 & 1 & 1 & 1 & 1 & 1 & 2 & 3 \\
\hline & 19 & 1 & 1 & 1 & 1 & 2 & 3 & 3 \\
\hline & 20 & 1 & 1 & 1 & 1 & 1 & 2 & 3 \\
\hline & 21 & 3 & 3 & 3 & 3 & 3 & 5 & 5 \\
\hline & 22 & 1 & 1 & 1 & 2 & 2 & 3 & 3 \\
\hline & 23 & 1 & 1 & 3 & 3 & 4 & 4 & 4 \\
\hline & 24 & 3 & 5 & 5 & 5 & 5 & 5 & 5 \\
\hline & 25 & 1 & 1 & 1 & 1 & 1 & 1 & 1 \\
\hline & 26 & 3 & 3 & 3 & 5 & 5 & 5 & 5 \\
\hline & 27 & 1 & 1 & 1 & 1 & 1 & 1 & 1 \\
\hline & 28 & 1 & 1 & 3 & 3 & 4 & 4 & 4 \\
\hline & 29 & 1 & 1 & 1 & 3 & 4 & 4 & 5 \\
\hline & 30 & 1 & 1 & 1 & 3 & 4 & 4 & 5 \\
\hline
\end{tabular}

Source: own elaboration.

the product based on randomness because of the lack of an appropriate decision model. Additionally, the operator has no knowledge about the location of the goods. 
The interpretation of the table regarding order quantity is as follows:

- product B was ordered three times in the first period [first day],

- product $\mathrm{C}$ was ordered two times in the second period [second day],

- Product $\mathrm{F}$ was ordered twelve times in the third period [third day].

Table 4 shows the delivery date - the vertical axis shows the number of channels inside the shuttle racks, while the horizontal axis shows the number of pallet places inside the channel. The interpretation of the table contents is as follows:

- the pallet in the fourth pallet place in channel number four will be delivered on the second day,

- the pallet in the third pallet place in channel number one will be delivered on the first day,

After interpreting the tables regarding the location of products in the warehouse, order quantity, stock level in relation to orders and delivery date, the next stage is to perform simulation that will show the impact of the variables discussed above on process efficiency.

Taking into account the application of the model, the study created multidimensional simulations including test examples necessary to establish the most effective model. The main aim of changing the parameters was to find the best configuration in the shuttle racks. In order to find a solution to avoid blockages and create an appropriate model, two approaches were used. The first approach was to modify the quantities of orders for various products, the second approach was to change the storage place of items inside the shuttle racks. Both approaches contributed to minimize blockages, but the second approach will be the subject of further research. The table below presents the results of the simulation to modify the quantities of orders. In this type of test task, the first step was to analyse the stock level relative to orders. The basis of the data for analysis is shown in Table 2, whereas Table 3 shows the relation between available stock levels and orders. Based on this information, it is possible to perform simulations. The decision model used in the simulations identified blockages during the outbound process, and provided information about number of orders not completed in the selected period, undelivered products and the time period of blockages.

Table 5 contains the simulation results. Moreover, each test example is discussed later in the article.

In the test example N01, product B was analysed. In the case of product B, the quantities of order were changed in the fourth period, but the model showed that the change of the quantity of order in this case did not cause blockages.

Summing up this test example, the change in the quantity of orders did not affect the blocking of goods. The main components of the results' interpretation were:

- solution time $-0.33 \mathrm{sec}$.,

- number of constraints - 951,

- number of variables - 1491 ,

- number of iterations -911 . 
Table 5. Test examples

\begin{tabular}{|c|c|c|c|c|c|c|c|c|c|c|c|c|c|c|c|}
\hline 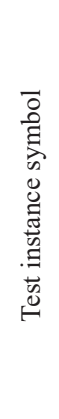 & $\begin{array}{l}\overline{0} \\
\tilde{O} \\
0 \\
\text { D. }\end{array}$ & 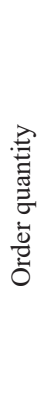 & 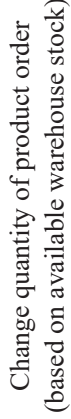 & 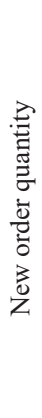 & 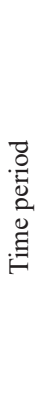 & 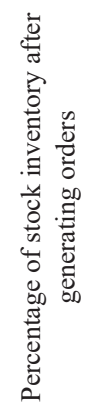 & 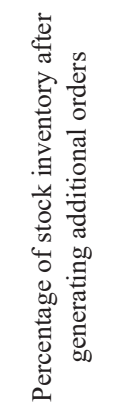 & 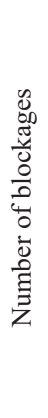 & 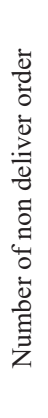 & 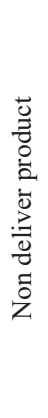 & 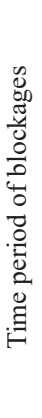 & 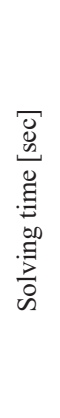 & 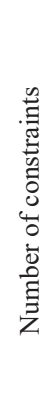 & 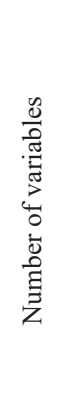 & 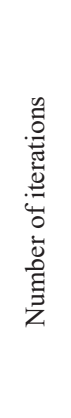 \\
\hline N01 & B & 1 & +9 & 10 & 4 & $59,09 \%$ & $100,00 \%$ & 0 & 0 & 0 & 0 & 0.33 & 951 & 1491 & 911 \\
\hline N02 & $\mathrm{C}$ & 1 & +26 & 27 & 5 & $35,00 \%$ & $100,00 \%$ & 1 & 12 & 3 & 5 & 0.45 & 951 & 1491 & 2022 \\
\hline \multirow{3}{*}{ N03 } & \multirow{3}{*}{ C } & \multirow{3}{*}{2} & \multirow{3}{*}{+26} & \multirow{3}{*}{28} & \multirow{3}{*}{2} & \multirow{3}{*}{$35,00 \%$} & \multirow{3}{*}{$100,00 \%$} & \multirow{3}{*}{3} & 1 & 4 & 1 & \multirow{3}{*}{0.75} & \multirow{3}{*}{951} & \multirow{3}{*}{1491} & \multirow{3}{*}{3333} \\
\hline & & & & & & & & & 1 & 10 & 1 & & & & \\
\hline & & & & & & & & & 6 & 3 & 2 & & & & \\
\hline \multirow{2}{*}{ N04 } & \multirow{2}{*}{ E } & \multirow{2}{*}{1} & \multirow{2}{*}{+8} & \multirow{2}{*}{9} & \multirow{2}{*}{3} & \multirow{2}{*}{$71,43 \%$} & \multirow{2}{*}{$100,00 \%$} & \multirow{2}{*}{2} & 1 & 5 & 5 & \multirow{2}{*}{0.31} & \multirow{2}{*}{951} & \multirow{2}{*}{1491} & \multirow{2}{*}{1341} \\
\hline & & & & & & & & & 1 & 10 & 5 & & & & \\
\hline \multirow{4}{*}{ N05 } & B & 1 & +9 & 10 & 4 & \multirow{4}{*}{$52,22 \%$} & \multirow{4}{*}{$100,00 \%$} & \multirow{4}{*}{3} & 10 & 3 & 5 & \multirow{4}{*}{0.92} & \multirow{4}{*}{951} & \multirow{4}{*}{1491} & \multirow{4}{*}{3347} \\
\hline & $\mathrm{C}$ & 1 & +26 & 27 & 5 & & & & & & & & & & \\
\hline & \multirow{2}{*}{ E } & 1 & +8 & 0 & 3 & & & & 3 & 5 & 2 & & & & \\
\hline & & & & & & & & & 1 & 10 & 1 & & & & \\
\hline
\end{tabular}

Source: own elaboration.

The second test example - N02, concerned product $\mathrm{C}$, the quantities of the order were changed in the fifth period. In relation to the test example of product $\mathrm{B}$, test example of product $\mathrm{C}$ provided completely different results despite the fact that were still available quantities in the warehouse stock. The model used during the simulation N02, identified blockages, the same as the inability to complete the order and deliver it to the customer according to order and delivery time (in this case the fifth time period). The interpretation of the result is as follows - on the fifth day there was a lack of product $\mathrm{C}$ for twelve orders.

The main components of the results interpretation were:

- solution time $-0.45 \mathrm{sec}$.,

- number of constraints - 951,

- number of variables - 1491 ,

- number of iterations - 2022 .

Another assumption from the test example was to the change delivery date from the fifth day to the second day. This case was included in the test example N03, however, this was still concerning product $\mathrm{C}$. The quantities of the order were 
changed from two units [pallets] to twenty eight units [pallets] in the second period, because twenty six units were available in the warehouse stock. The decision model identified blockages once again. The interpretation of the results is as follows:

- on the first day there was a lack of product D for one order,

- on the first day there was a lack of product J for one order,

- on the second day there was a lack of product $\mathrm{C}$ for six orders.

The main components of the results interpretation were:

- solution time $-0.75 \mathrm{sec}$.,

- number of constraints - 951,

- number of variables - 1491 ,

- number of iterations - 3333 .

In order to obtain a full picture of the simulations carried out, another test example was made for product E. Test example N04 presented the change of order quantities from one unit [pallet] to nine units [pallets] in the third period because eight units were available from the warehouse stock. In this case, the model also identified blockages. The interpretation of the results was as follows:

- on the fifth day there was a lack of product $\mathrm{E}$ for one order,

- on the fifth day there was a lack of product $\mathrm{J}$ for one order.

The main components of the results interpretation were:

- solution time $-0.31 \mathrm{sec}$.,

- number of constraints - 951,

- number of variables - 1491 ,

- number of iterations - 1341 .

The test examples analysed so far were based on individual cases for each article. In addition, to obtain the full picture about these considerations, the variant of parallel changes in the change quantities of orders for products $\mathrm{B}, \mathrm{C}$ and $\mathrm{E}$ had to be analysed. The key assumptions in this analysis were to change the quantities of orders at the same time. First of all, it was necessary to verify the stock level. Based on this, it is clear what inventory level is available and what quantities of orders can be generated. In this case the main task of the decision model was to identify blockages when changing the quantities for several products. Moving on to the analysis stage, the quantities of the orders were changed for products $\mathrm{B}, \mathrm{C}$ and $\mathrm{E}$ in parallel - according to Table 5, test example N05. In case of test example N05, the decision model also identified blockages, but because of the complexity of the case, the solution time was longer compared to the previously considered test examples. The main components of the results interpretation:

- solution time - $0.92 \mathrm{sec}$.,

- Number of constraints - 951,

- number of variables - 1491 ,

- number of iterations - 3347 .

Table 6 presents the blockages occurring for simulation N05 - the vertical axis shows the products, while the horizontal axis shows the time period (the unit of time 
is a day). Based on the orders included in Table 2, the order processing begins in the warehouse. The forklift operator receives commands to the mobile terminal and based on demand, selects from the list of locations where the product is located. In this case, the operator uses a random approach, because he/she has no knowledge about the location of goods in the warehouse. Taking into account the construction of the shuttle racks and comparing the location of products in relation to orders, in some cases it is not possible to collect goods because of blockages. The interpretation of the table contents is as follows:

- on the first day there was a lack of product $\mathrm{J}$ for one order,

- on the second day there was a lack of product $\mathrm{E}$ for three orders,

- on the fifth day there was a lack of product $\mathrm{C}$ for twelve orders.

Table 6. Blockages occuring in the case of simulation N05

\begin{tabular}{|c|c|c|c|c|c|c|}
\hline & \multicolumn{5}{|c|}{ Blockages } \\
\hline & & \multicolumn{5}{|c|}{ Time period [days] } \\
\hline & & 1 & 2 & 3 & 4 & 5 \\
\hline \multirow{10}{*}{ 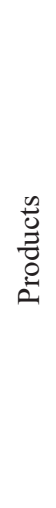 } & A & & & & & \\
\hline & B & & & & & \\
\hline & $\mathrm{C}$ & & & & & 12 \\
\hline & $\mathrm{D}$ & & & & & \\
\hline & E & & 3 & & & \\
\hline & $\mathrm{F}$ & & & & & \\
\hline & $\mathrm{G}$ & & & & & \\
\hline & $\mathrm{H}$ & & & & & \\
\hline & I & & & & & \\
\hline & $\mathrm{J}$ & 1 & & & & \\
\hline
\end{tabular}

Source: own elaboration.

After identifying blockages it was necessary to reorganize and relocate the warehouse stock to eliminate them. The decision model considered in this paper identified blockages, but all the relocation and reorganization activities will be considered in further research.

\section{Conclusion}

The implementation of temporary solutions provided information about the scale of the problem, but this was not sufficient to completely solve it. The system does not include the sequence in picking orders. The system should generate pallet movements related to the relocation of pallets due to blockages. In order to completely solve this 
problem, it is necessary to create a decision model which will take into account all the aspects and implement it to the system and its normal work. The key point of the decision model is the assigning process. The pallets should move out from shuttle racks according to the orders. Additionally, during the receiving goods from production, the system should indicate where the goods should be stored so that it would be possible to pick up the goods without blockages.

In recent years, the Shuttle-Based and Retrieval System have become the preferred solutions for automated warehouses in cases of high throughput demands. SBS/RS performed with a considerable flexibility reduce energy consumption. The model given for SBS/RS in this paper could help warehouse designers and others with decisions related to system efficiency, and properly design shuttle racks considering the specificity of the product range.

Achieving the main goals will require further research. The next step will be to create the model with automatic relocation of products in the shuttle racks - in order to minimize the blockages and to control material movements. Another important aspect is the model of pallet movements (putting the product into the shuttle racks and picking it up from the shuttle racks) which includes a production plan and orders from customers. To increase the effectiveness of the picking process it is necessary to implement a model which includes a picking alley. After stabilizing the warehouse processes, the model should take into account the randomness of demand and the orders placed in their order of assignment to the shuttle location.

\section{References}

Bekker, J. (2013). Multi-objective buffer space allocation with the cross-entropy method. International Journal of Simulation Modelling, 12(1), 50-61.

Berlec, T., Kusar, J., Zerovnik, J., and Starbek, M. (2014). Optimization of a product batch quantity. Strojniski vestnik - Journal of Mechanical Engineering, 60(1), 35-42.

Carlo, H. J., and Vis, I. F. A. (2012). Sequencing dynamic storage systems with multiple lifts and shuttles. International Journal of Production Economics, 140(2), 844-853.

Dotoli, M., and Fanti, M. P. (2005). A coloured petri net model for automated storage and retrieval systems serviced by rail-guided vehicles: A control perspective. International Journal Computer Integrated Manufacturing, 18(2-3), 122-136.

Ekren, B. Y.(2016). Graph-based solution for performance evaluation of shuttle-based storage and retrieval system. International Journal of Production Research. doi: 10.1080/ 00207543.2016.1203076

Erkan, T. E., and Can, G. F. (2014). Selecting the best warehouse data collecting system by using AHP and FAHP methods. Technical Gazette, 21(1), 87-93.

Ekren, B. Y., Heragu, S. S., Krishnamurthy, A., and Malmborg Charles, J. (2010). Simulation based experimental design to identify factors affecting performance of AVS/RS. Computer \& Industrial Engineering, 58(1), 175-185.

Fukunari, M., and Malmborg, C. J. (2008). An efficient cycle time model for autonomous vehicle storage and retrieval systems. International Journal of Production Research, 46(12), 3167-3184.

Giordano, V., Zhang, J. B., Naso, D., and Lewis, F. (2008). Integrated supervisory and operational control of a warehouse with a matrix-based approach. IEEE Transactions on Automation Science and Engineering, 5(1), 53-70. doi:10.1109/TASE.2007.891472 
He, S. J., and Luo, J. (2009). Deadlock control of autonomous vehicle storage and retrieval systems via coloured timed petri nets and digraph tools. International Journal of Production Research, 47(12), 3253-3263.

Kłodawski, M. (2014). Problem przydziału artykułów do lokacji w funkcji minimalizacji kosztów obiektu logistycznego. Logistyka, (4).

Klodawski, M., Jachimowski, R., Jacyna-Golda, I., and Izdebski, M. (2018). Simulation analysis of order picking efficiency with congestion situations. International Journal of Simulation Modelling, 17(3), 431-443.

Krishnamurthy, A., Roy, D., Heragu, S.S., Charles, J. M. (2010). Blocking effects on performance of warehouse systems with autonomous vehicles, Progress in Material Handling Research.

Lerher, T. (2013). Modern automation in warehousing by using the shuttle-based technology. In D. Arent, and M. Freebush (Eds.), Automation systems of the 21st Century: New technologies, applications and impacts on the environment \& industrial processes (pp. 51-86). New York: Nova Science Publishers.

Lerher, T., Ekren, B. Y., Banu, Y., and Sari, Z. (2015). Simulation analysis of shuttle based storage and retrieval systems. International Journal of Simulation Modelling, 14, 48-59. doi: 10.2507/ IJSIMM14(1)5.281

Lerher, T., Ekren, B. Y., Dukic, G., and Rosi, B. (2015). Travel time model for shuttle-based storage and retrieval systems. The International Journal of Advanced Manufacturing Technology, 78(9-12), 1705-1725. doi: 10.10 07/s0 0170-014-6726-2

Lerher, T., Edl, M., and Rosi, B. (2014). Energy efficiency model for the mini-load automated storage and retrieval systems. International Journal of Advanced Manufacturing Technology, 70(1-4), 97-115.

Le-Anh, T., and De Koster, M. B. M. (2006). A review of design and control of automated guided vehicle systems. European Journal of Operational Research, 171(1), 1-23.

Li, Z., NaiQi, W., and MengChu, Z. (2012). Deadlock control of automated manufacturing systems based on petri nets - a literature review. IEEE Transactions on Systems, 42(4), 437-462.

Lienert, T., and Fottner, J. (2017). No more deadlocks - applying the time window routing method to shuttle system. Proceedings 31st European Conference on Modelling and Simulation.

Liu, T., Xu, X., Qin, H., and Lim, A. (2015). Travel time analysis of the dual command cycle in the split-platform AS/RS with I/O dwell point policy. Flexible Services and Manufacturing Journal, 28(3), 442-460.

Malmborg, C. J. (2002). Conceptualizing tools for autonomous vehicle storage and retrieval systems. International Journal of Production Research, 40(8), 1807-1822.

Malmborg, C. J. (2003). Interleaving dynamics in autonomous vehicle storage and retrieval systems. International Journal of Production Research, 41(5), 1057-1069.

Marchet, G., Melacini, M., Perotti, S., and Tappia, E. (2013). Development of a framework for the design of autonomous vehicle storage and retrieval systems. International Journal of Production Research, 51(14), 4365-4387.

Marchet, G., Melacini, M., Perotti, S., and Tappia, E. (2012). Analytical model to estimate performances of autonomous vehicle storage and retrieval systems for product totes. International Journal of Production Research, 50(24), 7134-7148.

Roodbergen, K. J., and Vis, I. F. A. (2009). A survey of literature on automated storage and retrieval systems. European Journal of Operational Research, 194(2), 343-362.

Smew, W., Young, P., and Geraghty, J. (2013). Supply chain analysis using simulation, Gaussian process modelling and optimisation, International Journal of Simulation Modelling, 12(3), 178-189.

Vasili, M. R., Tang, S. H., Homayouni, S. M., and Ismail, N. (2008). A statistical model for expected cycle time of Sp-As/Rs: An application of Monte Carlo simulation. Application of Artificial Intelligence, 22(7-8), 824-840. 
Viswanadham, N., Narahari, Y., Timothy, and Johnson L. (1990). Deadlock prevention and deadlock avoidance in flexible manufacturing systems using petri net models. IEEE Transactions on Robotic and Automation, 6(6), 713-723.

Wang, Y., Mou, S., and Wu, Y. (2015). Task scheduling for multi-tier shuttle warehousing systems. International Journal of Production Research. 53(19), 5884-5895. doi: 10.1080/00207543. 2015.1012604

Ya-Hong, H., Ying Huang, S., Chen, C., Hsu, W.-J., Toh, A. C., Loh, C. K., and Song, T. (2005). Travel time analysis of a new automated storage and retrieval system. Computers \& Operation Research, 3(6), 1515-1544.

Zizzi, D. V. (2000). What's new in the equipment field. International Material Handling Research Colloquium, Material Handling. 